\title{
Metal oxide nanoparticles for the decontamination of toxic chemical and biological compounds
}

\section{(Chemical and biological toxics degradation by metal oxide Nanoparticles)}

\author{
Elodie Denet ${ }^{1 *}$, Maria Betzabeth Espina-Benitez, ${ }^{2,3^{*}}$, Isabelle Pitault, ${ }^{2}$ Thierry Pollet, ${ }^{4}$ Didier \\ Blaha, ${ }^{1}$ Marie-Alexandrine Bolzinger, ${ }^{2,3}$ Veronica Rodriguez Nava, ${ }^{1}$ Stéphanie Briançon, ${ }^{2,3}$ \\ ${ }^{1}$ Université Claude Bernard Lyon 1, Laboratoire d'Ecologie Microbienne (UMR CNRS 5557, INRA \\ 1418), Villeurbanne, France \\ 2 Université Claude Bernard Lyon 1, CNRS, LAGEPP UMR 5007, 43 boulevard du 11 novembre 1918, \\ F-69100, Villeurbanne, France ; \\ ${ }^{3}$ Université Claude Bernard Lyon 1, Laboratoire de Dermopharmacie et Cosmétologie, Institut des \\ Sciences Pharmaceutiques et Biologique, F-69373, Villeurbanne, France ; \\ ${ }^{4}$ OUVRY SAS, 24 av. Joannès Masset, F-69009 Lyon, France \\ * elodie.denet@univ-lyon1.fr and maria-betzabeth.espina-benitez@univ-lyon1.fr \\ ${ }^{¥}$ Contributed equally to this work
}

\section{ABSTRACT}

For several years, the international context is deeply affected by the use of chemical and biological weapons. The use of CBRN (Chemical Biological Radiological Nuclear) threat agents from military stockpiles or biological civilian industry demonstrate the critical need to improve capabilities of decontamination for civilians and military.

Physical decontamination systems that operate only by adsorption and displacement such as Fuller's Earth, have the drawback of not neutralizing hazardous agents, giving place to cross contaminations. Consequently, the development of a formulation based on metal oxide nanoparticles attracts considerable interest, since they offer physicochemical properties that allow them to both adsorb and degrade toxic compounds.

Thus, the aim of this study is to found metal oxide nanoparticles with a versatile activity on both chemical and biological toxic agents. Therefore, several metal oxides such as $\mathrm{MgO} \mathrm{TiO}_{2}, \mathrm{CeO}_{2}, \mathrm{ZnO}$ and $\mathrm{ZrO}_{2}$ were characterized and their 5-hours decontamination kinetics of less-toxic surrogate of VX, paraoxon, were studied in vitro. To determine the antimicrobial activity of these nanoparticles, simulants of biological terrorist threat were used by performing a 3-hours decontamination kinetics. This proof-of-concept study showed that $\mathrm{MgO}$ is the only one that exhibits both chemical and antibacterial actions but without sporicidal activity.

Key words: Chemical warfare agents, nanoparticles, metal oxide, antibacterial activity, sporicidal activity, chemical decontamination

\section{INTRODUCTION}

For several years, the international context is deeply affected by the use of chemical (chlorine bombs in Syria) and biological weapons (terrorist release of Bacillus anthracis spores through the U.S. Postal Service) ${ }^{1}$. The use of CBRN (Chemical Biological Radiological Nuclear) threat agents from military 
stockpiles or biological civilian industry demonstrate the critical need to improve capabilities of decontamination for civilians and military.

Indeed, during a biological or chemical attack, decontamination must be carried out immediately in order to limit the spread of the toxic agents. Current solutions such as bleach, washing with water and soap, or applying absorbent powder such as Fuller's Earth, are often unsatisfying because they generate toxic waste ${ }^{2}$ that must be treated since they do not neutralize hazardous agents ${ }^{3}$. These residual toxics can secondarily contaminate other people or materials, producing crosscontamination. Moreover, the need of a dry decontamination system, with multifunctional action and which generates little contaminated waste, is crucial for the various actors in the field (military, first responders, etc.).

The development of nanotechnology and its use in variety of fields have been booming since decade. Therefore, a formulation based on metal oxide (MO) nanoparticles (NPs) attracts considerable interest, since they offer promising outcomes such as small particle size, high specific surface area and unique physicochemical properties which allow them to both adsorb and degrade toxic compounds thanks to their catalytic activity ${ }^{4,5}$. Among the commonly studied metallic oxide NPs, $\mathrm{ZnO}, \mathrm{MgO}^{6}$ and $\mathrm{CaO}^{7}$ are of particular interest because they have chemical and antimicrobial activity with the advantage of being stable under harsh process conditions, such as high-temperature applications ${ }^{2,8}$.

As for the use of MO in Chemical Warfare Agents (CWA) decontamination, there are many research articles and patents that have been published ${ }^{2}$. For example, the commercial product Fast-Act ${ }^{\circledR}$ based on $\mathrm{MgO}$ and $\mathrm{TiO}_{2}$, have been developed by NanoScale Corporation, in order to degrade warfare agents, such as sulfur mustard, soman, and VX agent ${ }^{9}$. Likewise, Wagner et al. (2012) have studied hydrolysis of $\mathrm{VX}, \mathrm{GD}$, and $\mathrm{HD}$ on $\mathrm{TiO}_{2}$ materials for the development of self-decontaminating paints that can be used to protect military vehicles ${ }^{10}$. Indeed, the phosphorus atom in organophosphorus compounds carries a positive charge in the molecule and thus becomes highly electrophilic and reactive towards nucleophiles ${ }^{2,11}$. Therefore, the organophosphorus compounds are likely to hydrolyze at a rate that depends on the chemical structure of the molecule and reaction conditions such as the polarity and $\mathrm{pH}$, primarily in aqueous solutions ${ }^{12}$.

Several authors have focused their studies on the screening of synthesized MO by in-vitro tests that allow to select the MO with the most efficient degradation of chemical toxic agents and to understand the mechanism behind it. The in-vitro tests are usually performed by putting in contact a solution of the toxic compound in water or organic solvent, such as n-hexane or n-heptane, with the $\mathrm{MO}$ under stirring ${ }^{4,13-16}$. Most of recent research works have studied the degradation efficiency by $\mathrm{CeO}_{2}$ and $\mathrm{CeO}_{2}$ composites of organophosphorus nerve agents such as GD, VX and pesticides such as parathion with rapid and highly-efficient conversion of the toxic into non-toxic products ${ }^{3,13,14,17}$.

Furthermore, due to their physicochemical characteristics and broad spectrum of biological activity, metal oxide NPs have attracted great interest in several others areas. Indeed, they are widely used in (i) biomedical applications such as bone regeneration ${ }^{18}$ (ii) pharmaceutical products for the treatment of dermatological disorders ${ }^{19}$ and (iii) cosmetology such as sunscreen, creams, deodorants ${ }^{20}$. Antibacterial proprieties of metal oxide NPs have already been reported in several studies. $\mathrm{ZnO}$ or $\mathrm{MgO}$ could inhibited the growth of (i) opportunistic pathogens such as Pseudomonas aeruginosa and Staphylococcus aureus ${ }^{21}$, (ii) phytopathogenic bacteria such as Xanthomonas oryzae pv. oryzae ${ }^{22}$ and Ralstonia solanacearum ${ }^{23}$, (iii) pathogenic bacteria from food such as Campylobacter jejuni ${ }^{24}$ and Salmonella enteridis ${ }^{25}$. Although many studies have been carried out on antibacterial properties of metal oxide NPs, most of them only focus on one bacterial specie or one metal oxide without making a comparison between the performances of several metal oxides. Moreover, in the literature few reports are interested in observing in the same time chemical degradation and antibacterial activities in order to found a versatile metal oxide. 
Thus, the aim of this work is to study a series of metal oxide nanoparticles in order to select the best one in terms of both chemical and biological decontamination. Firstly, several $\mathrm{MO}$ such as $\mathrm{MgO} \mathrm{TiO}_{2}$, $\mathrm{CeO}_{2}, \mathrm{ZnO}$ and $\mathrm{ZrO}_{2}$ were characterized in terms of surface, morphology and crystalline structure. Then, a chemical decontamination kinetics of less-toxic surrogates of organophosphorus warfare agents, such as paraoxon (POX), has been carried out in-vitro. In addition, the antimicrobial activity of these NPs was investigated by performing a decontamination kinetic study on simulants of biological threat such as Escherichia coli, Staphylococcus aureus, Yersinia enterocolitica and Pseudomonas aeruginosa.

\section{Materials and methods}

\subsection{Materials}

Paraoxon-ethyl (p-phosphate, nitrophenyl, 0, O-diethyl), purity $90 \%$, density $1.27 \mathrm{~g} / \mathrm{ml}$ and paranitrophenol (PNP), 99 \% purity, were purchased from Sigma Company (St Quentin Fallavier, France). Isopropanol ( $\geq 99 \%$ ) was obtained from VWR (Fontenay-sous-Bois, France). Methanol and glacial acetic acid were obtained from Fisher Scientific (Leicestershire, United Kingdom).

Cerium oxide, magnesium oxide $<50 \mathrm{~nm}$ (MgO-2), titanium oxide, magnesium oxide-325 mesh (MgO-1), zirconium oxide and zinc oxide were commercial products obtained from different suppliers.

\subsection{Methods}

\subsubsection{Characterization of metal oxides}

Metal oxides were characterized by X-ray crystallography (XRD), transmission electron microscopy (TEM), and Brunauer, Emmett and Teller specific surface area (BET).

Powder X-ray diffraction (XRD) patterns were collected at the Henri Longchambon Diffractometry Center (University Lyon 1, Villeurbanne France) using a Bruker D8 Advance diffractometer equipped with a sealed $\mathrm{Cu}$ X-ray tube $(40 \mathrm{kV}, 40 \mathrm{~mA}, 0.15406 \mathrm{~nm})$ and a Lynxeye XE linear detector. Data were collected in the range of 5 to $70^{\circ}$ with $0.02^{\circ}$ steps. The lattice parameters and crystallite sizes were determined by profile matching using the elementary pseudo-Voigt function with the FullProf program packages.

Transmission electron microscopy (TEM) was performed with a Philips CM120 microscope at the Centre Technologique des Microstructures (CT $\mu$ ) of the University Lyon 1 (Villeurbanne, France). One night before the observation, a 10- $\mu \mathrm{L}$ drop of metal oxide suspension in isopropanol was placed on a microscope grid (carbon-coated copper support) and dried in the open air. The samples were observed by TEM under acceleration voltage of $120 \mathrm{kV}$.

Nitrogen adsorption isotherms were measured at $77 \mathrm{~K}$ on a Gemini 2390 VII (Micromeritics Instrument (Corp) with approximately $0.2 \mathrm{~g}$ of sample. Before the measurements, the samples were outgassed under vacuum for $4 \mathrm{~h}$ at $373 \mathrm{~K}$. The surface area was determined by the BrunauerEmmett-Teller (BET) approach. The total porous volume was measured at $\mathrm{P} / \mathrm{PO}=0.98$. The pore size distribution (max radius) and the mesoporous volume were calculated from the adsorption branch of the isotherms using the Barrett-Joyner-Halenda (BJH) model.

\subsubsection{Protocol of POX in-vitro degradation}

A $200 \mu \mathrm{mol} / \mathrm{L}(0.055 \mathrm{~g} / \mathrm{L})$ solution of paraoxon ethyl (POX) was prepared in isopropanol. For each degradation experiment, $200 \mathrm{mg}$ of nanoparticles were introduced into glass vials and then $2 \mathrm{~mL}$ of POX solution was added. Each sample was placed at $25^{\circ} \mathrm{C}$ in a thermostat bath under magnetic agitation at $550 \mathrm{rpm}$ during 4 hours to facilitate interactions between NPs and POX. Each experiment was carried out in duplicate. A $200 \mu \mathrm{mol} / \mathrm{L}$ solution of POX without nanoparticles was used as the 
negative control. The degradation of POX was measured by periodic sampling of solution and quantification of POX and PNP (first expected degradation product) using high pressure liquid chromatography (HPLC-DAD). The solution containing nanoparticles was centrifuged at 7,000 rpm for $2 \mathrm{~min}$, every $30 \mathrm{~min}$ (or $15 \mathrm{~min}$ for rapid POX degradations). $100 \mu \mathrm{L}$ of supernatant was collected, diluted 1:10 in $\mathrm{MeOH}$ and filtered through a nylon membrane filter (pore size $45 \mathrm{~mm}$, diameter $13 \mathrm{~mm}$ ) before HPLC analysis. The same procedure was applied for the control sample. Also, the catalytic activity of anatase $\mathrm{TiO}_{2}$ in absence of UV irradiation was verified by using UV-resistant vials.

The HPLC-DAD Agilent Series 1200 was operated at $40 \mathrm{C}$, the column used was a Kinetex $5 \mu \mathrm{m}$ EVO $\mathrm{C}_{18} 100 \AA$ ( $\left.250 \times 4.6 \mathrm{~mm}\right)$ cartridge. The composition of the mobile phase was $65 \%$ methanol (HPLC grade, Fisher Scientific grade) and $35 \%$ demineralized water with $0.5 \%(\mathrm{v} / \mathrm{v})$ acetic acid (glacial acetic acid and analytical grade 1 ultrapure water, resistivity $>17 \mathrm{M} \Omega \mathrm{cm}$ ). The flow rate was $0.7 \mathrm{~mL} / \mathrm{min}$. The total execution time was $10 \mathrm{~min}$ and the injection volume $10 \mu \mathrm{L}$. The POX compound was specified using the peak area at a retention time of $5.5 \mathrm{~min}$, with UV absorption at $\lambda_{\max } 269 \mathrm{~nm}$. The POX calibration curve was linear in the concentration range from 0 to $50 \mu \mathrm{mol} / \mathrm{L}$ (depending on dilution, a maximum of $20 \mu \mathrm{mol} / \mathrm{L}$ is expected).

\subsubsection{Antibacterial and sporicidal activities}

The antibacterial activity of metal oxide nanoparticles ( $\mathrm{MgO}, \mathrm{ZnO}, \mathrm{CeO}_{2}, \mathrm{ZrO}_{2}$ and $\mathrm{TiO}_{2}$ ) was evaluated against Gram-negative bacteria such as Escherichia coli 54.127, Pseudomonas aeruginosa CIP 103467, Yersinia enterocolitica CIP 80.27 and Gram-positive bacteria with Staphylococcus aureus CIP 4.83 reference strains. These strains were purchased at Pasteur Institute (France). The sporicidal activity was tested on spores suspension of Bacillus subtilis DSM 618 (Merck, France) ready to use.

One day before each experiment, bacteria were sub-cultured in Luria-Bertani (LB) broth at $37^{\circ} \mathrm{C}$, and shaken at $180 \mathrm{rpm}$. overnight. Following that, bacterial suspensions were adjusted in order to obtain $1.10^{8}$ Colony Forming Units (CFU)/ ml. In a tube, $1 \mathrm{~mL}$ of each adjusted bacterial suspension or spore suspension was added to $100 \mathrm{mg}$ of metallic oxide nanoparticles powder. Tubes were incubated for $3 \mathrm{~h}$ at $37^{\circ} \mathrm{C}$ under agitation in order to enhance contact between bacteria/spores and nanoparticles. Samples were harvested at 0,1 and 3 hours and were serial diluted in $\mathrm{NaCl} 0.9 \% .100 \mu \mathrm{L}$ of each dilution was spread on Plate Count Agar (PCA) medium (Solabia, France) and incubated at $37^{\circ} \mathrm{C}$ for $24 \mathrm{~h}$. Living bacteria or vegetative cells were then enumerated the following day. These results were compared with control cultures containing adjusted bacterial or spores suspensions without any nanoparticles. Experiments were done in duplicate in two independent manipulations.

\section{Results}

\subsection{Screening of metal oxides - POX in-vitro degradation}

The in-vitro test was developed in order to rapidly screen several metal oxide NPs, based on their ability to degrade POX. The degradation of POX has been expressed in percentage of POX conversion:

$$
\% P O X \text { conversion }=\frac{C_{P O X, t=0}-C_{P O X, t}}{C_{P O X, t=0}} \times 100
$$

where $C_{P O X, t=0}$ is the concentration of POX $\left(\mu \mathrm{mol}^{-1} \mathrm{~L}^{-1}\right)$ before its contact with the metal oxide, and $C_{P O X, t}$ is the concentration of POX in the supernatant at each sampling during the degradation experiment.

The degradation of POX using metal oxide nanoparticles is shown in Fig. 1. The method used for the test gives information about the degradation activity of the particles in isopropanol at $25 \mathrm{C}$. The test is conducted with a large excess of NPs compared to POX ( $2 \mu \mathrm{mol}$ of POX per gram of metal oxide). The ratio of mole of POX per mole of each metal oxide are given in Fig. 1. 


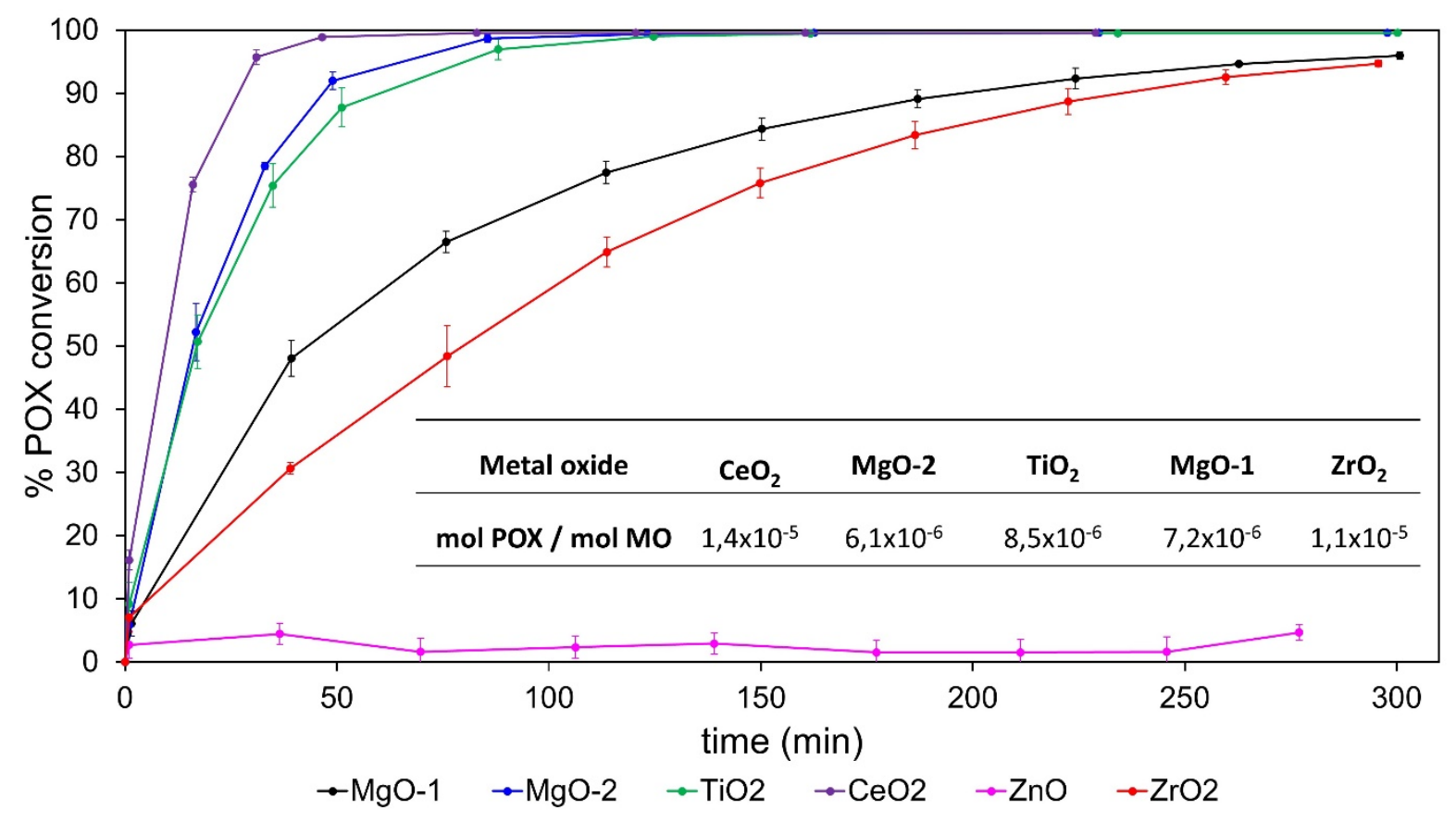

Fig. 1. Percentage of degradation of $\operatorname{POX}(200 \mu \mathrm{mol} / \mathrm{L}$ in isopropanol $)$ mixed with $200 \mathrm{mg}$ of metal oxide nanoparticles.

After 1 hour of contact, three groups of nanoparticles can be distinguished: the first group of nanoparticles, composed of $\mathrm{CeO}_{2}, \mathrm{MgO}-2$ and $\mathrm{TiO}_{2}$, allows the degradation of over $80 \%$ of the initial $\mathrm{POX}$, the second group of nanoparticles, $\mathrm{MgO}-1$ and $\mathrm{ZrO}_{2}$, degrades about $50 \%$ of the initial POX and the third group, $\mathrm{ZnO}$, is not able to degrade the POX. Among the nanoparticles of the first group, a faster degradation is observed during the first minutes with $\mathrm{CeO}_{2}$, followed by the $\mathrm{MgO}-2$ and then the $\mathrm{TiO}_{2}$. After 5 hours of contact, the POX is totally degraded by the first group and no degradation is observed with $\mathrm{ZnO}$. The second group has degraded $96.0 \%$ and $94.7 \%$ of the initial POX with MgO1 and $\mathrm{ZrO}_{2}$, respectively, after 5 hours. The stability of POX in 2-propanol during 5 hours without metal-oxide nanoparticles was also verified. The catalytic activity of anatase $\mathrm{TiO}_{2}$ was confirmed to be the same in absence or presence of UV irradiation (data not shown).

\subsection{Kinetic parameters of POX degradation}

The POX conversion over time has been adjusted to a first order kinetic model as follows:

$$
\ln \left(C_{P O X, t} / C_{P O X, t=0}\right)=-k t
$$

where $k$ is the reaction rate constant $\left[\mathrm{h}^{-1}\right]$ and $\mathrm{t}$ the reaction time. This relation comes from the mass balance equation, considering the liquid volume in the vial remained constant through the experiment:

$$
\frac{d n}{d t}=V \frac{d C}{d t}=-k C V
$$

with $\mathrm{C}$ the concentration, $\mathrm{V}$ the solution volume, $\mathrm{k}$ the kinetic constant and $\mathrm{t}$ the time.

Then, the half-life time, obtained from the Eq.2 for $C_{P O X, t}=\frac{1}{2} C_{P O X, t=0}$, is $\mathrm{t}_{1 / 2}=0.693 / \mathrm{k}$. The linear correlation $\ln \left(C_{P O X, t} / C_{P O X, t=0}\right)$ versus time for each metal oxide is shown in Fig. 2 and the values of $\mathrm{k}$ ant $\mathrm{t}_{1 / 2}$ are given in Table 1 . In the case of $\mathrm{ZnO}$, it is not possible to determine its kinetics parameters since it does not have a degradation activity on POX. 


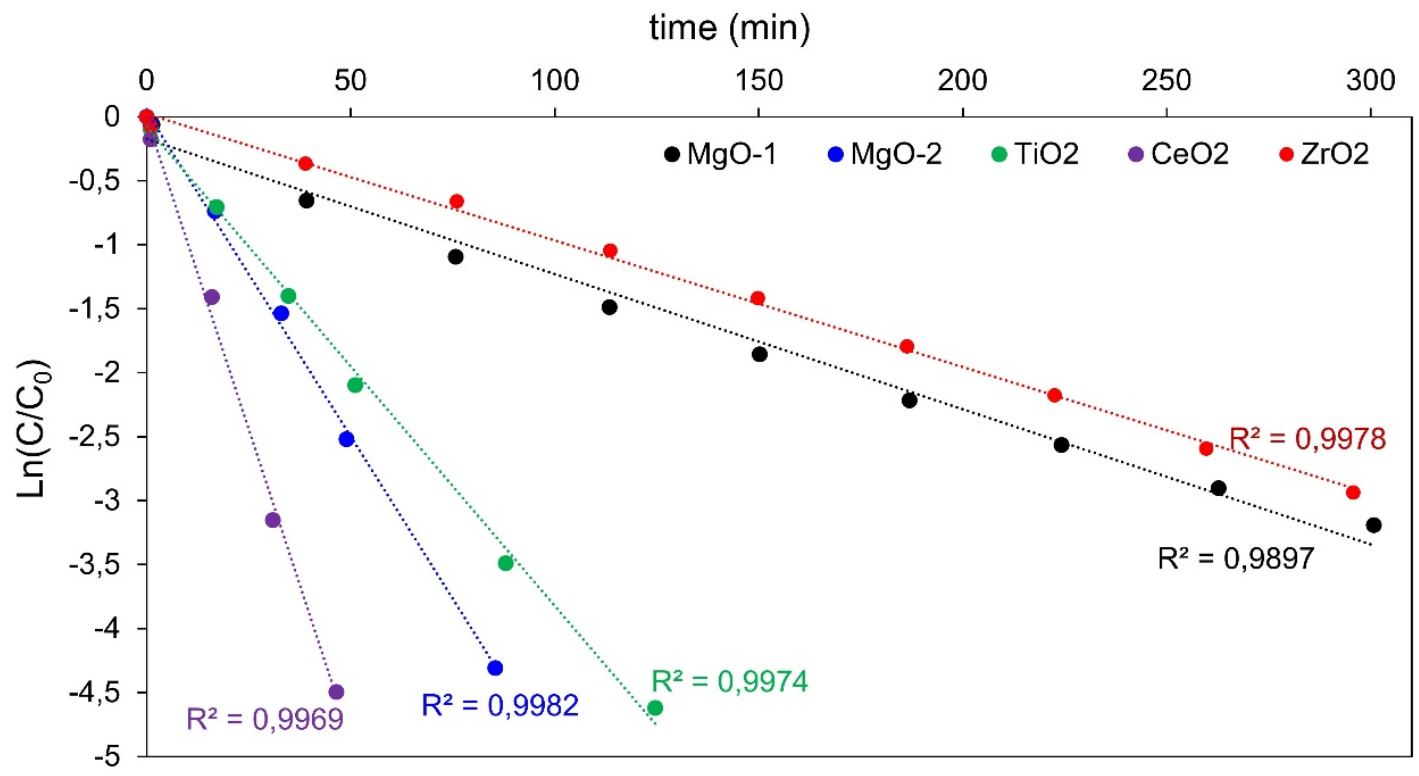

Fig. 2. Kinetics of POX degradation ( $200 \mu \mathrm{mol} / \mathrm{L}$ in isopropanol) mixed with $200 \mathrm{mg}$ of metal oxide nanoparticles.

Table 1. Kinetic constant and half-life time values for each metal oxide nanoparticles in our study and the kinetic parameters found in the literature.

\begin{tabular}{|c|c|c|c|c|c|c|c|c|}
\hline Metal oxide & $\mathrm{CeO}_{2}$ & $\mathrm{MgO}-2$ & $\mathrm{TiO}_{2}$ & $\mathrm{MgO}-1$ & $\mathrm{ZrO}_{2}$ & $\mathrm{CeO}_{2}{ }^{11}$ & $\mathrm{CeO}_{2}{ }^{11}$ & $\mathrm{CeO}_{2}^{13}$ \\
\hline Solvent & \multicolumn{5}{|c|}{ isopropanol } & n-heptane & acetonitrile & water \\
\hline Solvent relative polarity ${ }^{26}$ & \multicolumn{5}{|c|}{0.546 (protic) } & 0.0003 (aprotic) & 0.46 (aprotic) & 1 (protic) \\
\hline $\mathrm{k}\left(\mathrm{h}^{-1}\right)$ & 5,7 & 2,8 & 2,5 & 0,8 & 0,6 & 403,2 & 244,8 & 0,4 \\
\hline $\mathrm{t}_{1 / 2}(\mathrm{~min})$ & 7,3 & 14,9 & 16,9 & 50,5 & 74,1 & 0,1 & 0,17 & 113,8 \\
\hline
\end{tabular}

In Fig. 2, good correlations $\left(R^{2}>0.98\right)$ are observed for all the metal oxide nanoparticles, that indicate a good fit to a first order kinetic model. According to the values of $k$ and $t_{1 / 2}$ in Table 1 , the order of degradation of POX from faster to the slower is $\mathrm{CeO}_{2}>\mathrm{MgO}-2>\mathrm{TiO}_{2}>\mathrm{MgO}-1>\mathrm{ZrO}_{2}$, which is in agreement with the evolution of POX conversion over time in Fig. 2.

When comparing our results with $\mathrm{CeO}_{2}$ to those in the literature in different solvents, a trend is found: the more polar is the solvent used (water $>$ isopropanol $>$ acetonitrile $>n$-heptane) the slower is the degradation kinetics.

\subsection{Characterization of metal oxides}

Each metal oxide was characterized by Transmission Electron Microscopy (TEM), nitrogen adsorption and $X$-ray diffraction (XRD). The results of TEM, specific surface $\left(S_{B E T}\right)$, pore volume $\left(V_{p, N 2}\right)$, pore size, phase and crystal system, and particle size are presented in Fig. 3 . The relation between the kinetic constant of each $\mathrm{MO}$ and their surface properties $\mathrm{S}_{\mathrm{BET}}, \mathrm{V}_{\mathrm{p}, \mathrm{N} 2}$, pore size and particle size is presented in Fig. 4. 


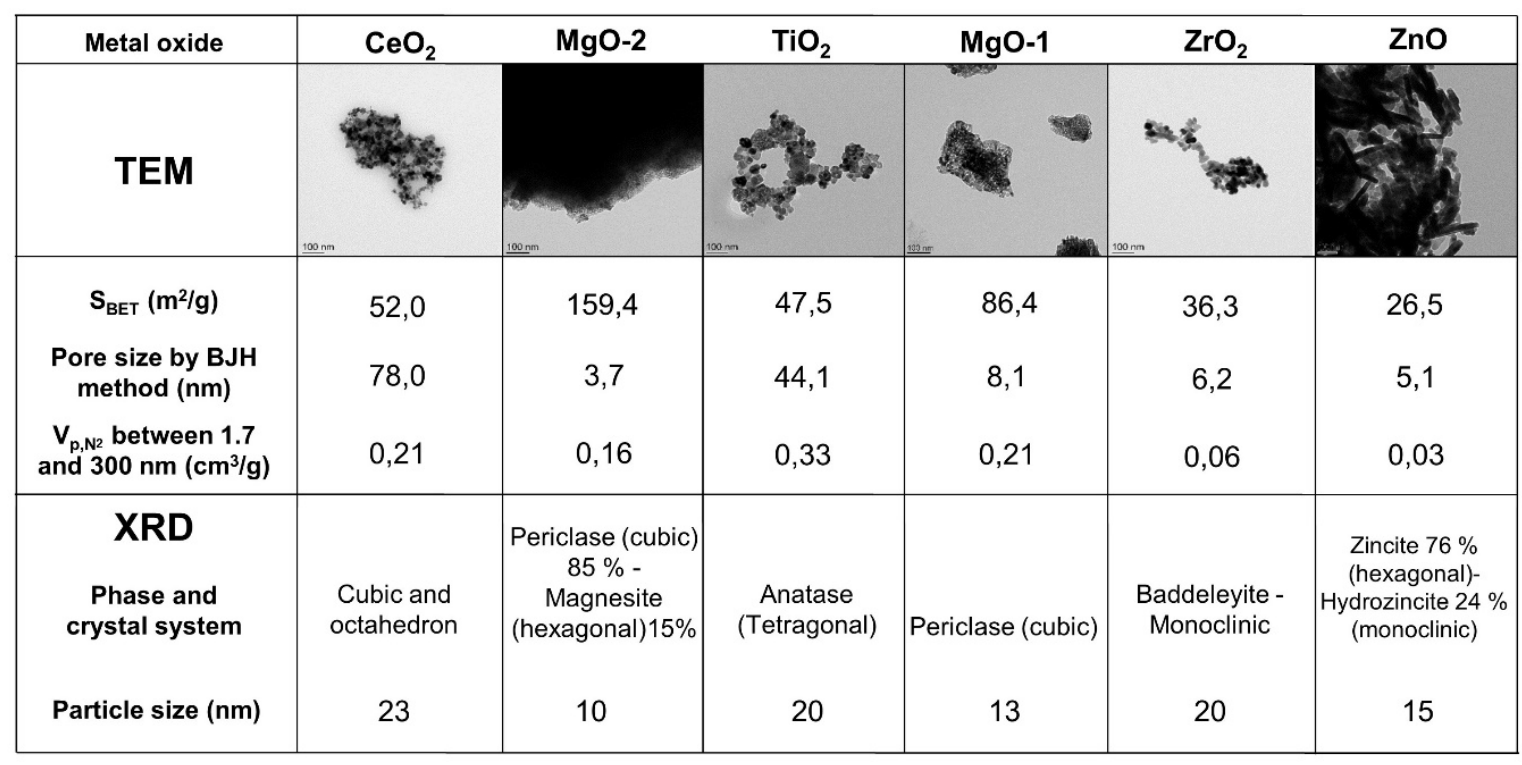

Fig.3. Characteristics of the metal oxide nanoparticles.
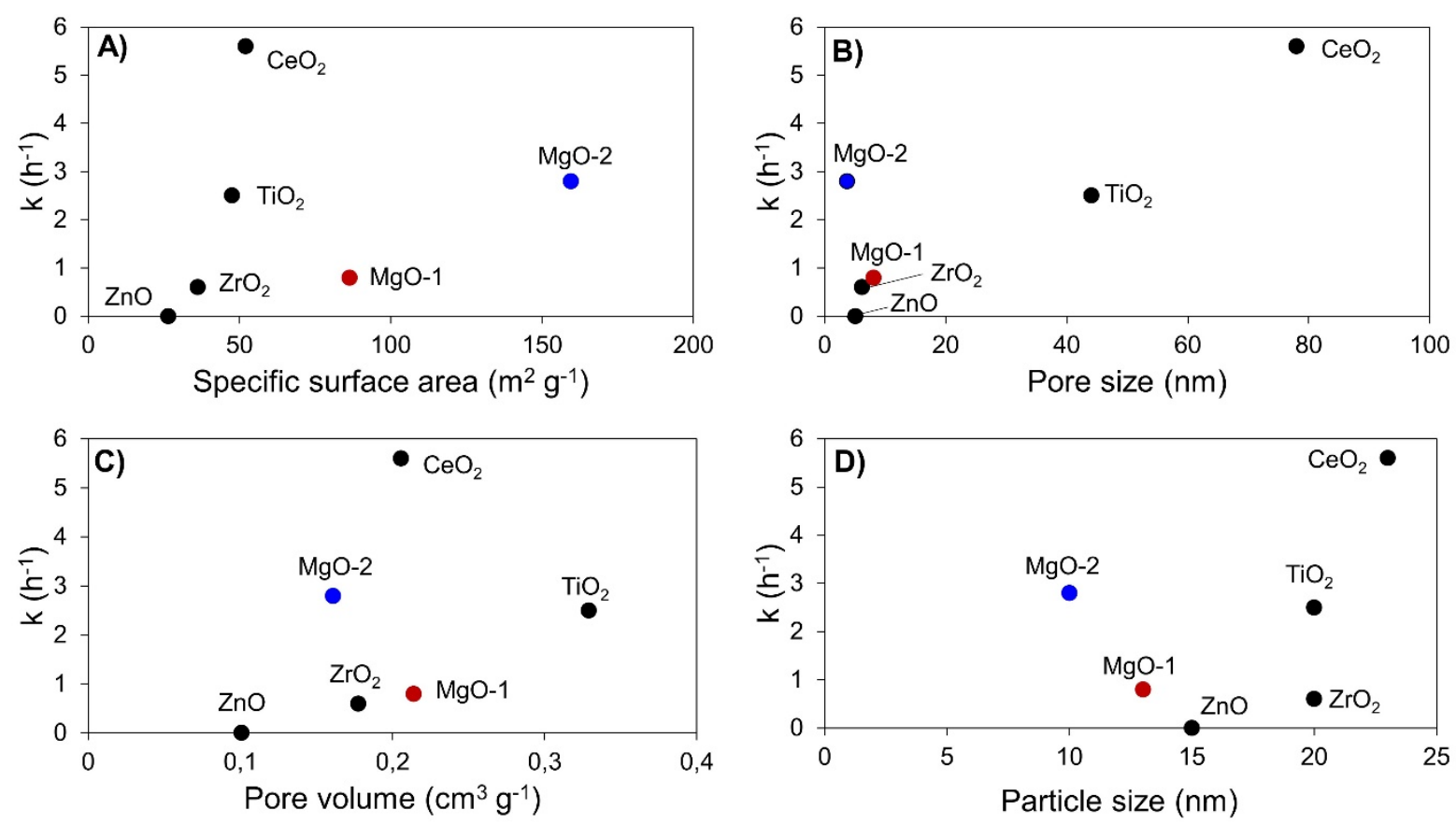

Fig. 4. Relation between the surface properties and the kinetics of POX degradation by each metal oxide: $A$ ) Kinetic constant vs. $\left.\mathrm{S}_{\mathrm{BET}}, \mathrm{B}\right)$ Kinetic constant vs. pore size, C) Kinetic constant vs. $\mathrm{V}_{\mathrm{p}, \mathrm{N} 2}$ and D) Kinetic constant vs. particle size. Blue and red dots represents the values obtained with $\mathrm{MgO}-2$ and $\mathrm{MgO}-1$, respectively.

All the metal oxides have a particle size between 10 and $23 \mathrm{~nm}$. $\mathrm{MgO}$ is the metal oxide with the higher specific surface, followed by $\mathrm{CeO}_{2}, \mathrm{TiO}_{2}, \mathrm{ZrO}_{2}$ and $\mathrm{ZnO}$. $\mathrm{TiO}_{2}$ is the metal oxide with the higher $\mathrm{V}_{\mathrm{p}, \mathrm{N} 2}$, followed by MgO-1, $\mathrm{CeO}_{2}, \mathrm{MgO}-2, \mathrm{ZrO}_{2}$ and $\mathrm{ZnO} . \mathrm{CeO}_{2}$ is the metal oxide with the higher pore size, followed by $\mathrm{TiO}_{2}, \mathrm{MgO}-1, \mathrm{ZrO}_{2}, \mathrm{ZnO}$ and $\mathrm{MgO}-2 . \mathrm{CeO}_{2}$ is a mix of cubic and octahedron particles as shown by TEM and XRD. $\mathrm{TiO}_{2}, \mathrm{MgO}-1$ and $\mathrm{ZrO}_{2}$ present monocrystalline particles: tetragonal $\mathrm{TiO}_{2}$, cubic $\mathrm{MgO}$ and monoclinic $\mathrm{ZrO}_{2} . \mathrm{ZnO}$ is a mix of hexagonal (zincite phase) and monoclinic (hydrozincite phase). And contrary to $\mathrm{MgO}-1, \mathrm{MgO}-2$ is a mix of cubic (periclase phase) and 
hexagonal (magnesite phase) nanoparticles. The presence of magnesite in $\mathrm{MgO}-2$ may be a residual product of its production process, since $\mathrm{MgO}$ can be obtained from the calcination of $\mathrm{Mg}(\mathrm{OH})_{2}{ }^{27,28}$.

\subsection{Antibacterial activity}

The antibacterial activity of several metallic oxide nanoparticles was investigated against E. coli, $Y$. enterocolitica, P. aeruginosa (Gram negative) and S. aureus (Gram positive). Fig. 5 represents $\log _{10}$ CFU $/ \mathrm{mL}$ values of bacterial simulant after treatment with $100 \mathrm{mg} / \mathrm{mL}$ of metallic oxide at the three different times (0, 1 and 3 hours).

(a)

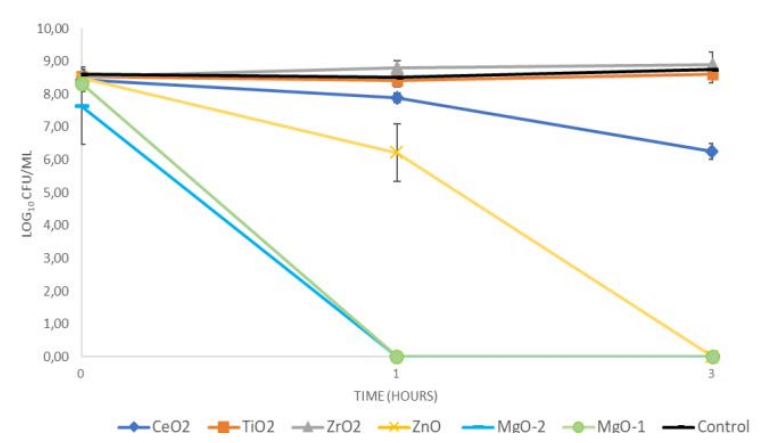

(c)

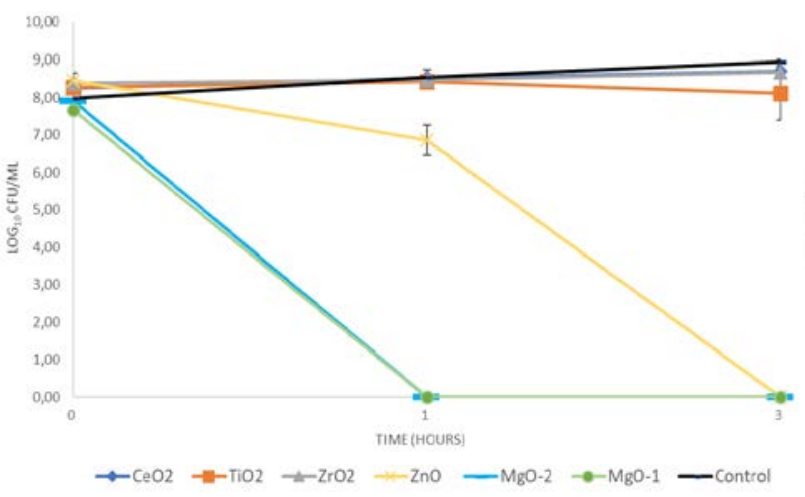

(b)

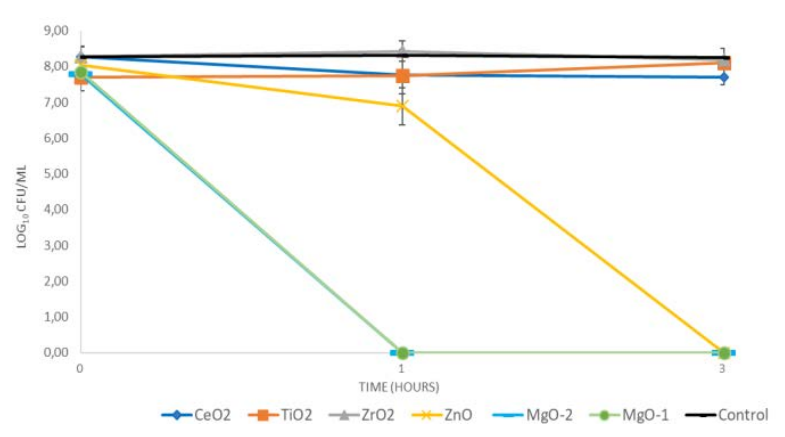

(d)

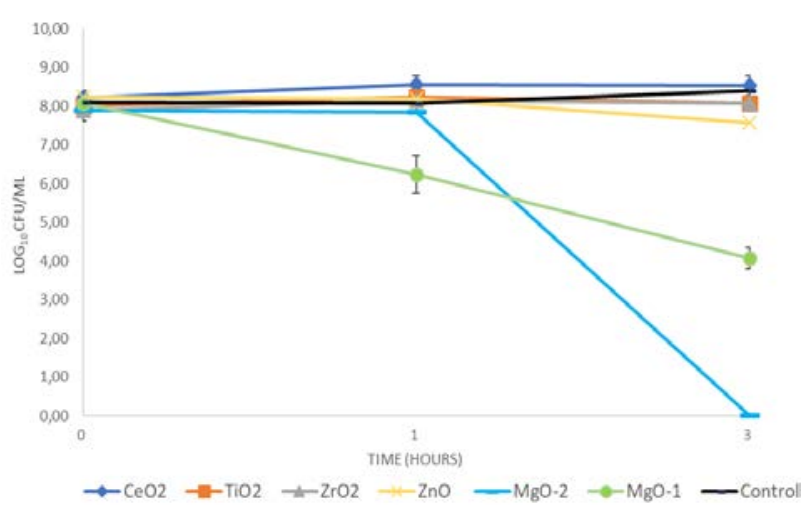

Fig. 5. Antibacterial effect of metallic oxide nanoparticles against $E$. coli (a), Y. enterocolitica (b), P. aeruginosa (c) and S. aureus (d). At 0, 1 and 3 hours, viable cell counts were counted by plating bacterial colonies on PCA medium. Each value represents the mean of two independent experiments realized in duplicate.

$\mathrm{CeO}_{2}, \mathrm{TiO}_{2}$ and $\mathrm{ZrO}_{2}$ have no antibacterial activity against the four bacteria tested. Indeed, the growth kinetics of these bacteria remains stable during the three hours as for the control condition. With $\mathrm{ZnO}$ nanoparticles, the growth of $E$. coli, $Y$. enterocolitica and $P$. aeruginosa was inhibited because no more bacteria have been counted following 3 hours of incubation (Fig. $5 a, b, c)$. We conclude that $\mathrm{ZnO}$ is bactericidal against these bacterial species after 3 hours of treatment. On the contrary, $\mathrm{ZnO}$ nanoparticles has no deleterious effect on the growth of $S$. aureus because it remains stable for 3 hours (Fig. 5d). This experiment showed that MgO-1 is bactericidal against E. coli, Y. enterolitica and $P$. aeruginosa after only one hour of treatment. However, $\mathrm{MgO}-1$ is not bactericidal against $\mathrm{S}$. aureus but it reduces the growth of this bacterial species as compared to the control (Fig. 5). Finally, MgO-2 has a good antibacterial activity because it is bactericidal against $E$. coli, $Y$. enterocolitica, $P$. aeruginosa after one hour of treatment and is bactericidal against $S$. aureus after 3 hours of treatment (Fig. 5). This analysis shows that $\mathrm{MgO}-2$ is the most efficient oxide for degrading both Gram-negative and Gram-positive bacteria. 


\subsection{Sporicidal activity}

The sporicidal activity of several metallic oxide nanoparticles was investigated using spores of Bacillus subtilis. Fig. 6 represents $\log _{10} \mathrm{CFU} / \mathrm{mL}$ values of vegetative cells after treatment with $100 \mathrm{mg} / \mathrm{mL}$ of metallic oxide at the three different times (0, 1 and 3 hours).

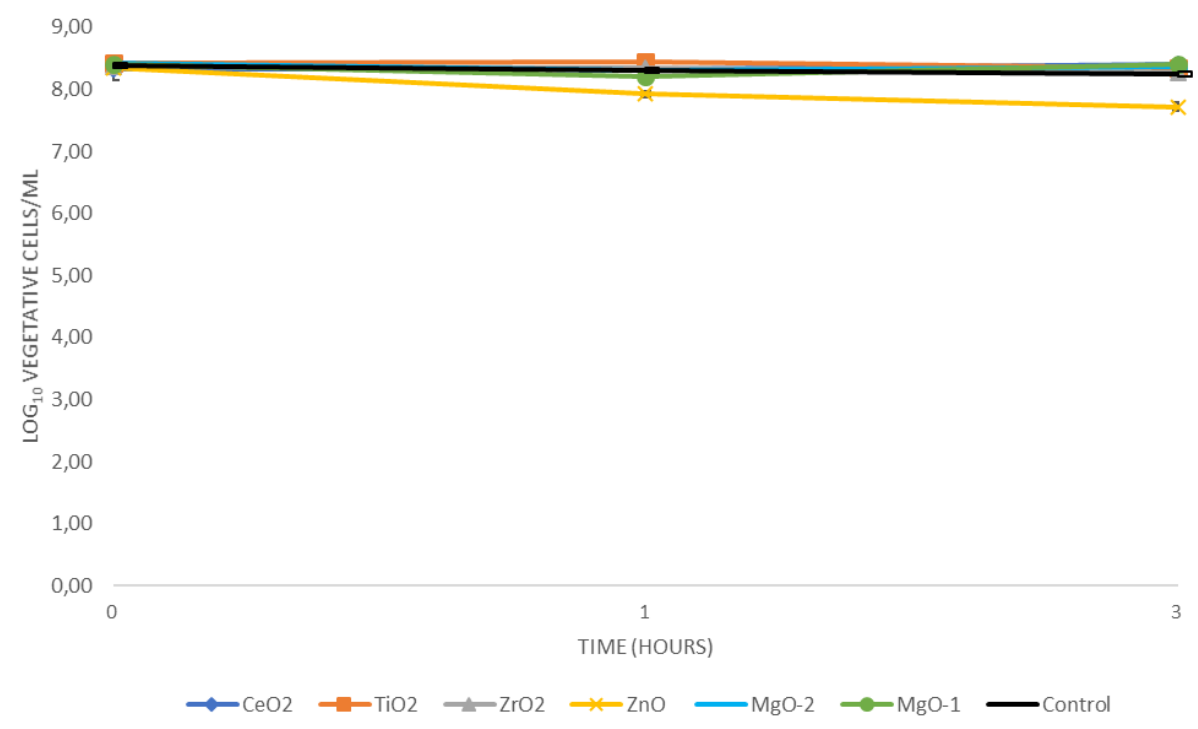

Fig. 6. Sporicidal effect of metallic oxide nanoparticles against spores of Bacillus subtilis. At 0, 1 and 3 hours of treatment, vegetative cells were counted by plating spore suspension on PCA medium. Each value represents the mean of two independent experiments realized in duplicate.

In comparison with the control condition, it appears that the treatment of $B$. subtilis spores with the different NPs of MO has no a significant impact on the number of viable vegetative cells recovered after 3 hours. Indeed, with all MO tested, the number of cells remains stable reaching about $1 \times 10^{8}$ vegetative cells $/ \mathrm{mL}$ as for the control condition. These results show that none of $\mathrm{MO}$ is sporicidal.

\section{Discussion}

Parameters such as the type, amount and concentration of nanoparticles, the amount or concentration of the toxic agent and the solvent nature have a significant influence not only on the degradation efficiency, but also on the kinetics and the degradation products that may be obtained $^{11,29}$. Reaching consensus on the effect of these parameters is difficult due to variation in experimental conditions between several studies published in the literature and especially the nature of solvents used. For example, few studies have used low ratios of toxic/metal oxide as in our work (2 $\mu \mathrm{mol}$ of POX per gram of metal oxide), however, this method allows to quickly select the most effective NPs for degradation of $\mathrm{POX}^{4,13}$.

The conditions used in our study are similar to those used by Trenque et al. (2019) ${ }^{13}$, with the exception of the solvent nature, these authors have used water instead of isopropanol. For the same type of crystal phase $\mathrm{CeO}_{2}$, mix of cubic and octahedral nanoparticles, the constant for a first-order kinetic model is $6.09 \times 10^{-3} \mathrm{~min}^{-1}\left(0.4 \mathrm{~h}^{-1}\right)$, a POX degradation 15 times slower than the one obtained in our study of $9.44 \times 10^{-2} \mathrm{~min}^{-1}\left(5.7 \mathrm{~h}^{-1}\right)$. Similar result was obtained by Janos et al. (2014) who studied the effect of solvent on stoichiometric degradation of some organophosphate pesticides. In their study, the authors observed that the degradation of methyl parathion by using cerium dioxide as a reactive sorbent in a non-aqueous environment occurred much more rapidly, in about 102 minutes, compared to about 102 hours or more in aqueous solution. In addition, they claimed to similarly degrade pesticides in non-polar and polar solvents with synthesized $\mathrm{CeO}_{2}$, with the exception of methanol, which had a negative effect on the degradation reaction ${ }^{11,30}$. 
These results (Table 1) indicate that the conversion of methyl parathion to 4-nitrophenol was slightly higher and faster in $n$-heptane than in acetonitrile with the same $\mathrm{CeO}_{2}$ nanopowder ${ }^{14,30}$. When analyzing the results of kinetic constant of the degradation of similar organophosphorus compounds (POX and parathion) in different solvents, it seems to be an effect of the polarity and nature (protic or aprotic) of the solvent on the degradation efficiency. Indeed, when using protic solvents the kinetics seems to be slower than with aprotic solvents such as acetonitrile or $n$-heptane. Janos et al. $(2014)^{11}$ have explained this effect as the $\mathrm{S}_{\mathrm{N}} 2$ nucleophilic substitution, for cleavage of the P-O-aryl bond in the organophosphorus molecule, is promoted in aprotic solvents. In addition, the polarity of the solvent has a negative effect on the organophosphate degradation kinetics.

This effect of the solvent on the degradation kinetics may be explained by its eluent strength, as a property that depends itself on the polarity. The eluent strength order of the solvents presented in Table 1 is water $>>$ isopropanol > acetonitrile $>\mathrm{n}$-heptane ${ }^{26}$, which means that the higher the eluent strength of the solvent, the slower is the degradation kinetics. As the eluent strength may be defined as the capacity of a solvent to displace the analyte by binding to the adsorbent in its place, it would mean that the use of high-eluent strength solvents such as water may avoid or interrupt the interaction between the organophosphorus compound and the metal oxide.

For this study, water was not possible to use since $\mathrm{MgO}$ nanoparticles hydrolyze and recrystallization occurs changing its crystal phase from periclase to brucite $\left(\mathrm{Mg}(\mathrm{OH})_{2}\right)$. Brucite has a lower degradation efficiency of $44,7 \%$ on POX (data not shown), compared to $96 \%$ when the periclase phase is maintained. Therefore, a mild-polarity organic solvent such as isopropanol was chosen.

Fully and rapid degradation of organophosphate compounds by metal oxide nanoparticles is rarely found in the literature. Most publications that present $100 \%$ conversion of the organophosphorus toxic in less than an hour or $\mathrm{t}_{1 / 2}<20$ min used alkaline metal-organic framework (MOF) powders ${ }^{31-33}$ or ceria composites ${ }^{34}$ as catalyst. The degradation efficiency of MOF is mostly justified by its high porosity and high specific surface area ${ }^{35,36}$, however, amine-based MOF such as N-ethylmorpholinebased MOF are not practical to store due to the high volatility of the N-ethylmorpholine ${ }^{32}$.

Organophosphate degradation by pure metal oxide nanopowders is rarely rapid or $100 \%$ complete in previous works, with the exception of $\mathrm{CeO}_{2}$, as demonstrated by Trenque et al. (2019) ${ }^{13}$. This is in agreement with the result obtained in our degradation test since $\mathrm{CeO}_{2}$ is the metal oxide that enables the fastest degradation of POX until $100 \%$ conversion in less than an hour.

Very rapid conversion of $\mathrm{POX}$ was also observed with $\mathrm{TiO}_{2}$ and $\mathrm{MgO}-2$, with even better performances than in the literature. In the case of $\mathrm{MgO}$, it has been showed a good catalytic activity on the degradation of different CWA such as soman (GD), VX, mustard gaz (HD) and their surrogates into non-toxic products, by hydrolysis reaction, thanks to its high specific surface area ${ }^{6,37-39}$. However, it usually presents either incomplete conversion of the toxic agent or $100 \%$ conversion in long-time reaction. In the case of $\mathrm{TiO}_{2}$, it is mostly used for its photocatalytic activity ${ }^{40-42}$ but, in the decontamination application, metal oxides may be used either under UV exposure or in its absence. Thus, the effect of the presence or absence of UV irradiation on its catalytic activity was also studied and the result showed an excellent degradation of POX in short-time even without UV exposure.

As well as in the literature ${ }^{37,43,44}$, the POX conversion with all of the metal oxides is well fitted to a first-order kinetic model, which indicates that the reaction rate is directly proportional to the POX concentration.

As reported, the main degradation product of POX is $\mathrm{PNP}^{6,13,37,45}$. As described by Trenque et al., the coordination between the phosphoryl oxygen and a metallic atom leads to the adsorption of the toxin; then a hydroxyl group coordinated with a metallic atom near the adsorption site acts as a nucleophile toward the $\mathrm{P}$ atom, and the subsequent $\mathrm{S}_{\mathrm{N}} 2$ reaction leads to the cleavage of the $\mathrm{P}-\mathrm{O}$ aryl bond, and the release of PNP ${ }^{2,11,13}$. In the case of a basic $\mathrm{MO}$, such as $\mathrm{MgO}$, Wagner el al. have 
reported that the degradation products of organophosphates are not released from the surface, but they stay grafted to it and that they can only be released at $\mathrm{pH}$ lower than $6^{37}$.

Researchers usually attribute the catalytic activity of MO NPs to their common characteristics such as: high specific surface area, mesoporosity, pore sizes from 2 to $12 \mathrm{~nm}$, particle size from 2 to $25 \mathrm{~nm}$ and the presence of highly reactive edges, corner defect sites and lattice planes ${ }^{46}$. In addition to these characteristics, the crystal structure plays a major role. Trenque et al $(2019)^{13}$ demonstrated the influence of the specific surface area and facets of $\mathrm{CeO}_{2}$ nanoparticles on POX degradation, with the activity of $\{111\}$ facets being greater than that of $\{100\}$ or poorly defined facets. The relative activity between the crystalline surfaces can be attributed to the probability of adsorption and to the surface density of the dipoles of Ce promoting the mimetic activity of the enzyme phosphatase of $\mathrm{CeO}_{2}$.

Even though several authors have used NPs with high specific area in order to increase organophosphorus CWA adsorption efficacy ${ }^{47,48}$, our results of characterization of the studied metal oxides show that there is not a clear relation between one particular characteristic and POX degradation (Fig. 4), especially regarding $\mathrm{MgO}$ results included in the graphics (blue and red dots for MgO-2 and MgO-1, respectively). In general, it seems that the higher the specific surface area, pore volume and size, the higher the catalytic activity.

$\mathrm{MgO}$ is one of the MOs with the highest specific surface, which is in agreement with what has been reported in previous works ${ }^{15,39}$ However, as observed in Fig. 3, the specific surface area can vary between two different $\mathrm{MgO}$ nanoparticles (MgO-1 and $\mathrm{MgO}-2$ ), depending on the production process. The presence of magnesite in $\mathrm{MgO}-2$ may increase the specific surface area and therefore, increase its catalytic activity. Indeed, this high specific surface area seems to compensate the low pore size in order to offer a complete and fast POX degradation.

Our results show precisely that MgO-2 exhibit the strongest bactericidal activity on both Gramnegative and positive bacteria. Also, this metal oxide has a specific surface measuring $159.4 \mathrm{~m}^{2} \cdot \mathrm{g}^{-1}$ which is much higher than the other oxides tested. These data are in accordance with other studies that have shown that bactericidal action of MgO NPs depends on the surface area available for interactions with bacteria ${ }^{49}$. MgO-2 is also the smallest NP since it measures $10 \mathrm{~nm}$. Several studies showed that nanoparticle size has an impact on the effectiveness of antibacterial activity ${ }^{8}$. Indeed, small nanoparticles exhibit a higher antibacterial activity because they can penetrate more easily within the bacteria wall and cause many damages ${ }^{8,50}$. Also, a study claimed that when the crystallite size decreases, the number of active surface sites increases which enhances the antibacterial activity 31.

The antibacterial performance of $\mathrm{ZnO}$ and MgO-1 NPs shows also a good activity but only on Gramnegative bacteria. Our data are in accordance with another study, which showed that ZnO exhibited a better antibacterial activity on E. coli (Gram-negative bacteria) than on S. aureus (Gram-positive bacteria $)^{19}$. However, other studies claimed the opposite since they show that $S$. aureus would be more sensitive to $\mathrm{ZnO}$ action than $E$. coli ${ }^{51,52}$. This difference of antibacterial effectiveness can be explained by the composition of the bacterial cell wall ${ }^{8}$. Indeed, Gram-negative bacteria have a complex cell wall composed by an outer membrane surmounted by lipopolysaccharides (LPS) molecules covering a thin layer of peptidoglycan ${ }^{8}$. Conversely, Gram-positive bacteria have no outer membrane but a thick layer of peptidoglycan and some bacterial species such as $S$. aureus can synthetize carotenoid pigments, which allow it to be more resistant to oxidative stress ${ }^{53}$. Then, as mentioned by Pasquet and her collaborators, each study in the literature justify its own experimental results with this difference in cell wall composition but unexplored factors may also be considered. Indeed, the exact mechanisms responsible for antibacterial activity of oxide metallic NPs are still unclear. Several mechanisms were highlighted in the literature with the production of Reactive Oxygen Species (ROS) such as hydrogen peroxide $\left(\mathrm{H}_{2} \mathrm{O}_{2}\right)$ by metal oxide NPs and damage to bacterial wall by electrostatic interaction ${ }^{23,25,54}$.These data show that the toxicity of oxide metallic NPs is 
complex it requires other mechanistic studies to elucidate the exact mechanisms responsible for antibacterial activity.

Our study indicates that $\mathrm{ZrO}_{2}, \mathrm{CeO}_{2}$, and $\mathrm{TiO}_{2}$ has no activity on the growth of the four bacterial strains tested. This is quite surprising because several studies demonstrated that these MO could inhibit the growth of bacterial pathogens such as $E$. coli, B. subtilis and $P$. aeruginosa ${ }^{55-58}$. Concerning $\mathrm{TiO}_{2}$ NPs, our experiments were performed with $\mathrm{TiO}_{2}$ alone and may explain the poor action efficiency of this $\mathrm{MO}$ on the four bacterial strain. Indeed, in the literature, the majority of the studies were performed with $\mathrm{TiO}_{2}$ in association with others NPs such as Ag NPs in order to have synergistic effects maximizing antibacterial activity ${ }^{59-61}$.In addition, our kinetic was executed in the dark without UV light illumination, which would limit antibacterial activity. Effectively, contrary of other $\mathrm{MO} \mathrm{TiO}_{2}$ is a NP, which can produce some toxic compounds such as ROS when it exposed to UV or visible light 59. However, studies have shown that despite the absence of UV radiation, $\mathrm{TiO}_{2}$ could still inhibit bacterial growth ${ }^{62}$. Even if, this activity in the dark remains lower than under light, $\mathrm{TiO}_{2}$ can reduce the viability of $E$. coli by $25 \%{ }^{59}$ whereas in our study no effect of bacterial viability was shown. Otherwise, studies shows that $\mathrm{TiO}_{2}$ crystalline structure is a factor that contributes to antibacterial activity. The anatase form is often the form in which $\mathrm{TiO}_{2}$ is the most effective, unlike the rutile form, which was less toxic ${ }^{63,64}$. This difference in toxicity between the two crystalline forms is related to the ability of each one to generate ROS ${ }^{65}$. In our study, TiO2 was in anatase form and no antibacterial activity was highlighted. This fact may be due that in our study no UV radiation was used unlike other studies. Concerning the bactericidal activity of $\mathrm{ZrO}_{2}$ or $\mathrm{CeO}_{2}$, literature is less documented than for others.

Our results showed that none of the tested $\mathrm{MO}$ is sporicidal. This is not surprising because spores are more resistant than vegetative cells to various stresses such as radiation, toxic chemicals, desiccation, and UV light ${ }^{66,67}$. Moreover, our experiments were realized with $\mathrm{MO}$ alone and not in association with another molecule. Indeed, some studies showed that doped $\mathrm{TiO}_{2}$ such as $\mathrm{Ag} /(\mathrm{C}, \mathrm{S})$ $\mathrm{TiO}_{2}$ or doped $\mathrm{MgO}$ such as $\mathrm{MgO}-\mathrm{Cl}_{2}$ are effective to kill Bacillus spores ${ }^{68,69}$. Then, it would be interesting to test several formulations with doped MO NPs in order to know if the sporicidal activity could be improved.

Taking into account the chemical and biological degradation activities, $\mathrm{MgO}-2$ is the most versatile MO. Indeed, it is bactericidal against the four surrogates and allows a fast and complete degradation of POX (in less than two hours. See Fig 1).

\section{Conclusion}

The kinetic study shows that $\mathrm{CeO}_{2}, \mathrm{TiO}_{2}$ and $\mathrm{MgO}-2$ have the fastest degradation of POX because 100 $\%$ conversion is reached in less than two hours. However, among these three MO, only MgO-2 has a good antibacterial activity against Gram-negative and Gram-positive bacteria. None of the tested MO have sporicidal activity, therefore, additional investigations are needed in order to find an efficient MO against spores. Considering that the aim of this study is to find the most versatile MO for chemical and biological degradation, $\mathrm{MgO}-2$ is the most performing nanoparticle. This $\mathrm{MO}$ has the smallest particle size and the highest specific surface area, which could explain its efficiency. Nevertheless, further studies need to be realized in order to understand the involved mechanisms in both chemical and biological degradation.

\section{Acknowledgements}

We thank the "Agence de l'Innovation de Defense" (AID) and "Direction Générale de l'Armement" (DGA) for their financial support (project ASTRID Maturation DENOTER - Grant N ANR-17-ASMA0004). The Centre de Diffractométrie Henri Longchambon are duly acknowledged for XRD facility and to Ruben Vera for carrying out the crystallographic analyses. We are grateful to Geraldine Agusti from University Lyon 1 for TEM observations at the Centre Technologique des Microstructures. We 
thank the help of Claudia Cogné and Laurent Garbit (IUT Génie de procédés, University of Lyon) for BET measurements.

\section{REFERENCES}

1. Canter, D. A. et al. Remediation of Bacillus anthracis contamination in the U.S. Department of Justice mail facility. Biosecurity and bioterrorism : biodefense strategy, practice, and science 3, 119-127 (2005).

2. Jang, Y. J., Kim, K., Tsay, O. G., Atwood, D. A. \& Churchill, D. G. Update 1 of: Destruction and detection of chemical warfare agents. Chem. Rev. 115, PR1-PR76 (2015).

3. Salerno, A. et al. In vitro skin decontamination of the organophosphorus pesticide Paraoxon with nanometric cerium oxide CeO2. Chemico-Biological Interactions 267, 57-66 (2017).

4. Salerno, A., Pitault, I., Devers, T., Pelletier, J. \& Briançon, S. Model-based optimization of parameters for degradation reaction of an organophosphorus pesticide, paraoxon, using $\mathrm{CeO} 2$ nanoparticles in water media. Environmental Toxicology and Pharmacology 53, 18-28 (2017).

5. Jain, S. et al. Enhanced antibacterial profile of nanoparticle impregnated cellulose foam filter paper for drinking water filtration. Carbohydrate Polymers 202, 219-226 (2018).

6. Sellik, A. et al. Degradation of paraoxon (VX chemical agent simulant) and bacteria by magnesium oxide depends on the crystalline structure of magnesium oxide. Chemico-Biological Interactions 267, 67-73 (2017).

7. Wagner, G. W., Koper, O. B., Lucas, E., Decker, S. \& Klabunde, K. J. Reactions of VX, GD, and HD with Nanosize CaO: Autocatalytic Dehydrohalogenation of HD. J. Phys. Chem. B 104, 5118-5123 (2000).

8. Tang, Z.-X. \& Lv, B.-F. MgO nanoparticles as antibacterial agent: preparation and activity. Braz. J. Chem. Eng. 31, 591-601 (2014).

9. Štengl, V. et al. From the Decomposition of Chemical Warfare Agents to the Decontamination of Cytostatics. Ind. Eng. Chem. Res. 57, 2114-2122 (2018).

10. Wagner, G. W., Peterson, G. W. \& Mahle, J. J. Effect of Adsorbed Water and Surface Hydroxyls on the Hydrolysis of VX, GD, and HD on Titania Materials: The Development of Self-Decontaminating Paints. Ind. Eng. Chem. Res. 51, 3598-3603 (2012).

11. Janos, P. et al. Cerium dioxide as a new reactive sorbent for fast degradation of parathion methyl and some other organophosphates. Journal of Rare Earths 32, 360-370 (2014).

12. Kulshreshtha, A. \& Shinde, C. P. A review: General base catalysis hydrolysis of organophosphorus insectisides by different amines. 3, 8 (2012).

13. Trenque, I. et al. Shape-selective synthesis of nanoceria for degradation of paraoxon as a chemical warfare simulant. Phys. Chem. Chem. Phys. (2019) doi:10.1039/C9CP00179D.

14. Henych, J. et al. Water-based synthesis of $\mathrm{TiO} 2 / \mathrm{CeO} 2$ composites supported on plasma-treated montmorillonite for parathion methyl degradation. Applied Clay Science 144, 26-35 (2017).

15. Armaghan, M. \& Amini, M. M. Adsorption of diazinon and fenitrothion on nanocrystalline magnesium oxides. Arabian Journal of Chemistry 10, 91-99 (2017).

16. Henych, J., Janoš, P., Kormunda, M., Tolasz, J. \& Štengl, V. Reactive adsorption of toxic organophosphates parathion methyl and DMMP on nanostructured Ti/Ce oxides and their composites. Arabian Journal of Chemistry (2016) doi:10.1016/j.arabjc.2016.06.002.

17. Janoš, P. et al. Cerium oxide for the destruction of chemical warfare agents: A comparison of synthetic routes. Journal of Hazardous Materials 304, 259-268 (2016).

18. Roh, H.-S. et al. Addition of MgO nanoparticles and plasma surface treatment of threedimensional printed polycaprolactone/hydroxyapatite scaffolds for improving bone regeneration. Materials Science and Engineering: C 74, 525-535 (2017).

19. Pasquet, J. et al. Antimicrobial activity of zinc oxide particles on five micro-organisms of the Challenge Tests related to their physicochemical properties. International Journal of Pharmaceutics 460, 92-100 (2014). 
20. Niska, K., Zielinska, E., Radomski, M. W. \& Inkielewicz-Stepniak, I. Metal nanoparticles in dermatology and cosmetology: Interactions with human skin cells. Chemico-Biological Interactions 295, 38-51 (2018).

21. Das, B. et al. Biosynthesis of magnesium oxide ( $\mathrm{MgO}$ ) nanoflakes by using leaf extract of Bauhinia purpurea and evaluation of its antibacterial property against Staphylococcus aureus. Materials Science and Engineering: C 91, 436-444 (2018).

22. Ogunyemi, S. O. et al. Green synthesis of zinc oxide nanoparticles using different plant extracts and their antibacterial activity against Xanthomonas oryzae pv. oryzae. Artificial Cells, Nanomedicine, and Biotechnology 47, 341-352 (2019).

23. Cai, L. et al. Magnesium Oxide Nanoparticles: Effective Agricultural Antibacterial Agent Against Ralstonia solanacearum. Frontiers in Microbiology 9, (2018).

24. Windiasti, G. et al. Investigating the synergistic antimicrobial effect of carvacrol and zinc oxide nanoparticles against Campylobacter jejuni. Food Control 96, 39-46 (2019).

25. He, Y. et al. Study on the mechanism of antibacterial action of magnesium oxide nanoparticles against foodborne pathogens. Journal of Nanobiotechnology 14, (2016).

26. Pagni, R. Solvents and Solvent Effects in Organic Chemistry, Third Edition (Christian Reichardt). J. Chem. Educ. 82, 382 (2005).

27. Birchal, V. S. S., Rocha, S. D. F. \& Ciminelli, V. S. T. The effect of magnesite calcination conditions on magnesia hydration. Minerals Engineering 13, 1629-1633 (2000).

28. Gehringer, S., Luckeneder, C., Hrach, F. \& Flachberger, H. Processing of Caustic Calcined Magnesite (Magnesium Oxide) by the Use of Triboelectrostatic Belt Separation. Berg Huettenmaenn Monatsh 164, 303-309 (2019).

29. Štengl, V., Grygar, T. M., Opluštil, F. \& Olšanská, M. Decontamination of sulfur mustard from printed circuit board using Zr-doped titania suspension. Ind. Eng. Chem. Res. 52, 3436-3440 (2013).

30. Štastný, M., Tolasz, J., Štengl, V., Henych, J. \& Žižka, D. Graphene oxide/MnO2 nanocomposite as destructive adsorbent of nerve-agent simulants in aqueous media. Applied Surface Science 412, 19-28 (2017).

31. Cho, K. Y. et al. Facile control of defect site density and particle size of UiO-66 for enhanced hydrolysis rates: insights into feasibility of $\mathrm{Zr}(\mathrm{IV})$-based metal-organic framework (MOF) catalysts. Applied Catalysis B: Environmental 245, 635-647 (2019).

32. Chen, Z., Islamoglu, T. \& Farha, O. K. Toward base heterogenization: A zirconium metal-organic framework/dendrimer or polymer mixture for rapid hydrolysis of a nerve-agent simulant. ACS Appl. Nano Mater. 2, 1005-1008 (2019).

33. Yao, A., Jiao, X., Chen, D. \& Li, C. Photothermally enhanced detoxification of chemical warfare agent simulants using bioinspired core-shell dopamine-melanin@metal-organic frameworks and their fabrics. ACS Appl. Mater. Interfaces 11, 7927-7935 (2019).

34. Janoš, P. et al. Magnetically separable reactive sorbent based on the $\mathrm{CeO} 2 / \mathrm{Y}-\mathrm{Fe} 2 \mathrm{O} 3$ composite and its utilization for rapid degradation of the organophosphate pesticide parathion methyl and certain nerve agents. Chemical Engineering Journal 262, 747-755 (2015).

35. Safaei, M. et al. A review on metal-organic frameworks: Synthesis and applications. TrAC Trends in Analytical Chemistry 118, 401-425 (2019).

36. Liu, Y. et al. Catalytic degradation of chemical warfare agents and their simulants by metalorganic frameworks. Coordination Chemistry Reviews 346, 101-111 (2017).

37. Wagner, G. W., Bartram, P. W., Koper, O. \& Klabunde, K. J. Reactions of VX, GD, and HD with nanosize MgO. J. Phys. Chem. B 103, 3225-3228 (1999).

38. Štengl, V. et al. Aerogel nanoscale magnesium oxides as a destructive sorbent for toxic chemical agents. cent.eur.j.chem. 2, 16-33 (2004).

39. Maddah, B. \& Chalabi, H. Synthesis of $\mathrm{MgO}$ and identification of their destructive reaction products by 2-chloroethyl ethyl sulfide. 8 (2012). 
40. Shen, Z. et al. Evolution of microstructural defects of TiO2 nanocrystals by Zr4+ or/and Ge4+ doping lead to high disinfection efficiency for CWAs. Chemical Physics Letters 678, 146-152 (2017).

41. Shen, Z. et al. Decontamination of Chemical Warfare Agents by Zn2+ and Ge4+ co-doped TiO2 nanocrystals at sub-zero temperatures: A solid-state NMR and GC study. Chemical Physics Letters 707, 31-39 (2018).

42. Komano, A. et al. Titanium dioxide photocatalytic decomposition of ethyl-S-dimethylaminoethyl methylphosphonothiolate (VX) in aqueous phase. Applied Catalysis B: Environmental 134-135, 19-25 (2013).

43. Juang, R.-S. \& Chen, C.-H. Comparative study on photocatalytic degradation of methomyl and parathion over UV-irradiated TiO2 particles in aqueous solutions. Journal of the Taiwan Institute of Chemical Engineers 45, 989-995 (2014).

44. Zboril, R. et al. Treatment of chemical warfare agents by zero-valent iron nanoparticles and ferrate(VI)/(III) composite. Journal of Hazardous Materials 211-212, 126-130 (2012).

45. Zhao, S. et al. Rapid activation of basic hydrogen peroxide by borate and efficient destruction of toxic industrial chemicals (TICS) and chemical warfare agents (CWAs). Journal of Hazardous Materials 367, 91-98 (2019).

46. Wagner, G. W. Decontamination of chemical warfare agents with nanosize metal oxides. in Nanoscale Materials in Chemistry: Environmental Applications vol. 1045 125-136 (American Chemical Society, 2010).

47. Štengl, V., Grygar, T. M., Opluštil, F. \& Němec, T. Ge4+ doped TiO2 for stoichiometric degradation of warfare agents. Journal of Hazardous Materials 227-228, 62-67 (2012).

48. Henych, J. et al. Degradation of organophosphorus pesticide parathion methyl on nanostructured titania-iron mixed oxides. Applied Surface Science 344, 9-16 (2015).

49. Bindhu, M. R., Umadevi, M., Kavin Micheal, M., Arasu, M. V. \& Abdullah Al-Dhabi, N. Structural, morphological and optical properties of $\mathrm{MgO}$ nanoparticles for antibacterial applications. Materials Letters 166, 19-22 (2016).

50. Nguyen, N.-Y. T., Grelling, N., Wetteland, C. L., Rosario, R. \& Liu, H. Antimicrobial Activities and Mechanisms of Magnesium Oxide Nanoparticles (nMgO) against Pathogenic Bacteria, Yeasts, and Biofilms. Scientific Reports 8, (2018).

51. Lallo da Silva, B., Caetano, B. L., Chiari-Andréo, B. G., Pietro, R. C. L. R. \& Chiavacci, L. A. Increased antibacterial activity of $\mathrm{ZnO}$ nanoparticles: Influence of size and surface modification. Colloids and Surfaces B: Biointerfaces 177, 440-447 (2019).

52. Arakha, M., Saleem, M., Mallick, B. C. \& Jha, S. The effects of interfacial potential on antimicrobial propensity of ZnO nanoparticle. Scientific Reports 5, (2015).

53. Liu, G. Y. et al. Staphylococcus aureus golden pigment impairs neutrophil killing and promotes virulence through its antioxidant activity. The Journal of Experimental Medicine 202, 209-215 (2005).

54. Sirelkhatim, A. et al. Review on Zinc Oxide Nanoparticles: Antibacterial Activity and Toxicity Mechanism. Nano-Micro Letters 7, 219-242 (2015).

55. Bellio, P. et al. Cerium oxide nanoparticles as potential antibiotic adjuvant. Effects of $\mathrm{CeO} 2$ nanoparticles on bacterial outer membrane permeability. Biochimica et Biophysica Acta (BBA) Biomembranes 1860, 2428-2435 (2018).

56. Pelletier, D. A. et al. Effects of Engineered Cerium Oxide Nanoparticles on Bacterial Growth and Viability. Applied and Environmental Microbiology 76, 7981-7989 (2010).

57. Wang, L. \& Meng, F. Oxygen vacancy and $\mathrm{Ce} 3+$ ion dependent magnetism of monocrystal $\mathrm{CeO} 2$ nanopoles synthesized by a facile hydrothermal method. Materials Research Bulletin 48, 34923498 (2013).

58. Tsuang, Y.-H. et al. Studies of Photokilling of Bacteria Using Titanium Dioxide Nanoparticles. Artificial Organs 32, 167-174 (2008).

59. Yan, Y. et al. Carbon quantum dot-decorated $\mathrm{TiO} 2$ for fast and sustainable antibacterial properties under visible-light. Journal of Alloys and Compounds 777, 234-243 (2019). 
60. Sharma, V. K. et al. Interactions between silver nanoparticles and other metal nanoparticles under environmentally relevant conditions: A review. Science of The Total Environment 653, 1042-1051 (2019).

61. Dias, H. B., Bernardi, M. I. B., Bauab, T. M., Hernandes, A. C. \& de Souza Rastelli, A. N. Titanium dioxide and modified titanium dioxide by silver nanoparticles as an anti biofilm filler content for composite resins. Dental Materials 35, e36-e46 (2019).

62. Vargas, M. A. \& Rodríguez-Páez, J. E. Facile Synthesis of TiO2 Nanoparticles of Different Crystalline Phases and Evaluation of Their Antibacterial Effect Under Dark Conditions Against E. coli. Journal of Cluster Science 30, 379-391 (2019).

63. Macwan, D. P., Dave, P. N. \& Chaturvedi, S. A review on nano-TiO2 sol-gel type syntheses and its applications. Journal of Materials Science 46, 3669-3686 (2011).

64. Vargas, M. A. \& Rodríguez-Páez, J. E. Amorphous TiO2 nanoparticles: Synthesis and antibacterial capacity. Journal of Non-Crystalline Solids 459, 192-205 (2017).

65. Anandgaonker, P., Kulkarni, G., Gaikwad, S. \& Rajbhoj, A. Synthesis of TiO2 nanoparticles by electrochemical method and their antibacterial application. Arabian Journal of Chemistry (2015) doi:10.1016/j.arabjc.2014.12.015.

66. Paul, M., Atluri, S., Setlow, B. \& Setlow, P. Mechanisms of killing of spores of Bacillus subtilis by dimethyldioxirane. Journal of Applied Microbiology 101, 1161-1168 (2006).

67. Atrih, A. \& Foster, S. J. Bacterial endospores the ultimate survivors. International Dairy Journal 12, 217-223 (2002).

68. Hamal, D. B. et al. A Multifunctional Biocide/Sporocide and Photocatalyst Based on Titanium Dioxide $\left(\mathrm{TiO}_{2}\right)$ Codoped with Silver, Carbon, and Sulfur. Langmuir 26, 2805-2810 (2010).

69. Koper, O. B. et al. Nanoscale Powders and Formulations with Biocidal Activity Toward Spores and Vegetative Cells of Bacillus Species, Viruses, and Toxins. Current Microbiology 44, 49-55 (2002). 